\title{
Malahit Yeşilinin Gideriminde Şeftali Çekirdeği Kabuğu: Karakterizasyon ve Kinetik İnceleme
}

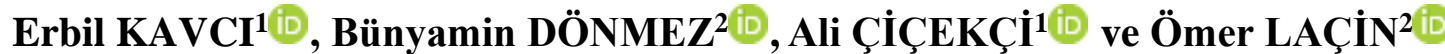

How to cite: Kavc1, E., Dönmez, B., Çiçekci, A., \& Laçin, Ö. (2021). Malahit yeşilinin gideriminde şeftali çekirdeği kabuğu: Karakterizasyon ve kinetik inceleme. Sinop Üniversitesi Fen Bilimleri Dergisi, 6(1), 9-20. https://doi.org/10.33484/sinopfbd.761068

\section{Araştırma Makalesi}

\section{Sorumlu Yazar}

Bünyamin DÖNMEZ

bdonmez@atauni.edu.tr

Yazarlara ait ORCID

E.K.: 0000-0001-6519-9901

B.D.: 0000-0002-7680-0755

A.Ç.: 0000-0001-7890-602X

Ö.L.: 0000-0002-5276-3056

Received: 01.07 .2020

Accepted: 18.12 .2020

\section{$\ddot{O} \mathbf{z}$}

$\mathrm{Bu}$ araştırmada, adsorbent olarak kullanılan şeftali çekirdeği kabuğu üzerine sulu ortamdaki malahit yeşilinin adsorpsiyonu amaçlanmıştır. Bunun için önce adsorbentin karakterizasyonu incelenmiş ve sonrasında adsorpsiyon prosesini etkileyen parametrelerden faydalanarak uygun bir kinetik model elde edilmiştir. Karakterizasyon çalışmalarında; Taramalı Elektron mikroskobu, Termal Gravimetri/Diferansiyel Taramalı Kalorimetri, Diferansiyel Termal Gravimetri, X-Işını Kırınımı ve Yüzey analizleri yapılmıştır. Termal Gravimetri/Diferansiyel Taramalı Kalorimetri analizleri ile, şeftali çekirdeğinin $25-150^{\circ} \mathrm{C}, 200-380^{\circ} \mathrm{C}$ ve $380-580^{\circ} \mathrm{C}$ sıcaklık aralıklarında bozunduğu gözlenmiştir. X-Işını Kırınımı analizleri sonucu ise, adsorbent yapısının amorf bir karaktere sahip olduğunu ortaya koymuştur. Ayrıca, yüzey analizleri ile, adsorbentin yüzey alanı, por hacmi ve ortalama por çapı değerleri belirlenmiştir. Adsorpsiyon prosesinin kinetiğinin belirlenmesi için, yaygın olarak kullanılan modeller incelenmiş ve kinetik modelin yalancı ikinci mertebeye uyduğu tespit edilmiştir. Elde edilen sonuçlar 1şı̆̆ında, endüstriyel anlamda sulu çözeltilerden malahit yeşilinin uzaklaştırılması hususunda şeftali çekirdeği kabuğunun oldukça katkı sağlayacağı söylenebilir.

Anahtar Kelimeler: Şeftali çekirdeği kabuğu, malahit yeşili, adsorpsiyon, karakterizasyon, kinetik model

\section{Peach Core Shell for Removal of Malachite Green: Characterization and Kinetics} Analysis

\footnotetext{
${ }^{1}$ Kafkas Üniversitesi, Kimya Mühendisliği Bölümü, Kars, Türkiye

${ }^{2}$ Atatürk Üniversitesi, Kimya Mühendisliği Bölümü, Erzurum, Türkiye
}

Bu çalışma Creative Commons Attribution 4.0 International License ile lisanslanmıştır

\begin{abstract}
In this research, adsorption of malachite green in aqueous medium on peach seed shell used as adsorbent was aimed. For this purpose, first the characterization of adsorbent was examined and then a proper kinetic model was obtained by using the parameters affecting the adsorption process. In characterization studies; Scanning Electron Microscope, Thermal Gravimetry/Differential Scanning Calorimetry, Differential Thermal Gravimetry, X-Ray Diffraction and Surface analysis were done. With Thermal Gravimetry/Differential Scanning Calorimetry analysis, it was observed that the peach kernel degraded at temperatures between 25$150^{\circ} \mathrm{C}, 200-380^{\circ} \mathrm{C}$ and $380-580^{\circ} \mathrm{C}$. As a result of X-Ray Diffraction analysis, it was revealed that the adsorbent structure has an amorphous character. In addition, by surface analysis, surface area, pore volume and average pore diameter values of the adsorbent were determined. In order to determine the kinetics of the adsorption process, commonly used
\end{abstract}


models were examined and it was found that the kinetic model fit the pseudo-second order. In the light of the results obtained, it can be said that the peach seed shell will contribute greatly to the removal of malachite green from aqueous solutions industrially.

Keywords: Peach kernel peel, malachite green, adsorption, characterization, kinetics model

\section{Giriş}

Tekstil, kağıt, deri, kozmetik, ilaç, gıda gibi birçok sektörde renklendirici olarak kullanılmakta olan boyar maddeler, kullanım sonrası bu sektörlerin atık sularında gözlenmektedir [1]. Bu kimyasallar, hem çevreye zarar vermekte hem de güneş 1şı̆̆ında parçalanamadıkları için bitkilerin fotosentezini de engelleyebilmektedirler. Ayrıca, kimyasal yapıları gereği, insan sağlığı için zararlı olup kanserojen özellik de taşımaktadırlar [2, 3]. Canlılar için oldukça tehlikeli ve atık sulardan giderilmesi oldukça zor olan boyar maddelerden birisi de malahit yeşili atığıdır.

Boyar madde giderimi; kimyasal, biyolojik ve fiziksel olmak üzere üç ayrı yöntemle yapılmaktadır. Kimyasal olarak koagülasyon ve flotasyon, biyolojik anlamda biyoparçalama ve fiziksel olarak da çöktürme, iyon değişimi, membran filtrasyonu, 1şınlama, ozonlama ve adsorpsiyon yöntemleri kullanılmaktadır [4-6]. Daha fazla kullanıma sahip olan fiziksel yöntemler içerisinde en çok tercih edileni adsorpsiyondur. Adsorbentin ucuzluğu, prosesin kolay uygulanabilmesi ve boyar madde tutma kapasitesinin yüksek olması, bu yöntemin en önemli avantajlarıdır [7, 8].

Adsorpsiyon işlemi, zaman esaslı bir prosestir. Adsorpsiyon sistemlerinin tasarımı, adsorpsiyon mekanizmasına ve kinetiğine bağlıdır. Kinetik modeller, adsorpsiyon süresini ve mekanizmasını belirleyen eşitliklere göre ortaya konulmuş denklemlerdir. Adsorpsiyon mekanizması ve süresi, adsorbentin fiziksel ve kimyasal özellikleri yanı sıra, sıcaklık, pH ve karıştırma hızı gibi parametrelere de bağlıdır.

Adsorpsiyon proseslerinde kullanılan adsorbentlerden biri de şeftali çekirdeği kabuğudur. Latince ismi Prunus persica olan şeftali meyvesinin üretimi konusunda, ülkemizin önemli bir potansiyele sahip olduğu görülmektedir (Tablo 1). Şeftali çekirdeği bileşiminin kütlece \%6 civarında olması, ortalama y1ll1k 40.000 ton çekirdek miktarı demektir. Sonuç olarak, şeftali meyvesinin bir atığ1 olan ham şeftali çekirdeğinin iyi bir potansiyele sahip ve ekonomik olması, onun uygun bir adsorbent olarak kullanılabileceği anlamına gelmektedir.

Tablo 1.Türkiye şeftali üretimi ve miktarı [9]

\begin{tabular}{cc}
\hline İl & Üretim miktarı (ton) \\
\hline Mersin & 103.595 \\
Çanakkale & 91.558 \\
Bursa & 77.941 \\
İzmir & 74.311 \\
Antalya & 17.154 \\
Sakarya & 16.076 \\
Adana & 14.823 \\
\hline
\end{tabular}

Bu araştırmada, Taramalı Elektron Mikroskobu (SEM), Termal Gravimetri/Diferansiyel Taramalı Kalorimetri (TG-DSC), Diferansiyel Termal Gravimetri (DTG), X-Işını Kırınımı (XRD) ve Micrometrics 3Flex cihazı ile yüzey 
analizleri sonucu şeftali çekirdeği kabuğunun karakterizasyonu incelenmiştir. Ayrıca, sulu ortamda malahit yeşilinin şeftali çekirdeği kabuğu üzerine adsorpsiyon kinetiği de incelenmiştir.

\section{Materyal ve Metot}

\section{Adsorbent}

Antalya-Korkuteli'nden temin edilen ham şeftali çekirdeği kabuğu, temizlenip kurutulduktan sonra $250 \mu \mathrm{m}$ 'ye öğütülmüştür. Bir şeftali çekirdeği kabuğunun yaklaşık elementel analizi Tablo 2' de verilmiştir [10]

Tablo 2. Şeftali çekirdeğinin elementel analizi

\begin{tabular}{cc}
\hline Bileşen & Bileşimi $(\%, \mathrm{w} / \mathrm{w})$ \\
\hline $\mathrm{C}$ & 50.50 \\
$\mathrm{H}$ & 5.68 \\
$\mathrm{~N}$ & 0.07 \\
$\mathrm{O}$ & 43.75
\end{tabular}

Micrometrics 3Flex cihazı ile adsorbentin bazı yüzey özellikleri analiz edilmiş ve Tablo 3'de verilmiştir.

Tablo 3. Adsorbentin bazı yüzey özellikleri

\begin{tabular}{ccc}
\hline $\begin{array}{c}\text { Yüzey } \\
\text { Alanı } \\
\left(\mathrm{S}, \mathrm{m}^{2} \cdot \mathrm{g}^{-1}\right)\end{array}$ & $\begin{array}{c}\text { Por hacmi } \\
\left(\mathrm{Vp}, \mathrm{cm}^{3} \cdot \mathrm{g}^{-1}\right)\end{array}$ & $\begin{array}{c}\text { Ortalama Por } \\
\text { Çap } 1 \\
(\mathrm{dp}, \mathrm{nm})\end{array}$ \\
\hline 17.36 & 0.016 & 3.37 \\
\hline
\end{tabular}

\section{TG-DTG/DSC, XRD ve SEM Analizleri}

Adsorbente ait termal analizler NETZSCH STA 409 PC Luxx marka cihaz ile yapılmıştır. Cihazın denge ve sicaklık kontrol sistemi, 0.001 mg ağırlık kaybını ve $0.1 \mathrm{~K}$ sıcaklık değişimini hassas olarak ölçebilmektedir. Standart referans madde olarak kalsine edilmiş $\alpha-\mathrm{Al}_{2} \mathrm{O}_{3}$ tozu kullanılmıştır. Katı numuneler (yaklaşık 20 mg) bir pan içerisine yerleştirilmiş ve $10^{\circ} \mathrm{C} / \mathrm{dk}$ 'llk 1sitma hizinda hava atmosferinde $1000^{\circ} \mathrm{C}^{\prime}$ ye kadar isitılmıştır.

Bozundurma analizleri, eş zamanlı TG/DSC ve DTG cihazı ile gerçekleştirilmiştir. $\mathrm{Bu}$ eğrilerinden, şeftali çekirdeğinin kütle kayıpları ve karakteristik sıcaklık değerleri (reaksiyon başlama sıcaklığı, maksimum pik sicaklığı, reaksiyon sonu sıcaklığı) elde edilmiştir. TG/DSC analizleri ile, yüksek sıcaklık altında, ham şeftali çekirdeği ve malahit yeşili adsorplanmış şeftali çekirdeği kabuğunun bozunma eğrileri elde edilmiştir.

XRD analizinde, Panalytical Empryrean cihazı kullanılmıştır. Cihaz, $2 \Theta=0-90^{\circ}$ aralığında $\mathrm{Cu}$ $\mathrm{K} \alpha\left(\lambda=1.5405 \mathrm{~A}^{0}\right)$ radyasyonu şartlarında ölçüm yapmaktadır. SEM analizleri ise, A ZEISS SIGMA 300 analiz cihazında yapılmıştır.

\section{Adsorbat}

Merck firmasından temin edilen malahit yeşili, $\mathrm{C}_{23} \mathrm{H}_{25} \mathrm{~N}_{2} \mathrm{Cl}$ kimyasal formülüne sahiptir (mol kütlesi $=364.92$ g.mol-1, C.I. Sinıflandırma Numaras1 42.000, CAS 569-64-2, $\lambda \max =617$ $\mathrm{nm})$. Malahit yeşili, çoğu ülkede kullanımı yasaklanmasına rağmen, ucuzluğu ve kolay bulunabilmesinden dolayı özellikle yün, ipek, deri veya pamuğun boyanmasında ayrıca kağıt üretimi, gıda teknolojisi ve zirai ilaç endüstrisinde antiseptik olarak da kullanılmaktadır $[11,12]$.

Adsorpsiyon denemelerinde, öncelikle 1000 ppm'lik malahit yeşili stok çözeltisi hazırlanmış ve tüm deneylerde bu stok çözeltisi 
kullanılmıştır. Adsorpsiyon denemeleri, 250 mL'lik şilifli erlenler içerisinde, hava banyolu çalkalayıcı ortamda (Edmund Bühler Gmbh KS15) kesikli olarak gerçekleştirilmiştir. Her bir deneme için, 50-100-150-200 ve 250 ppm malahit yeşili içeren çözeltilerden $50 \mathrm{~mL}$ alınmış ve 1 gram adsorbent ilave edilerek denge süresine kadar $(120 \quad \mathrm{dk})$ denemeler sürdürülmüsstür. Deneylerde çözelti ortamı sıcaklığ $125^{\circ} \mathrm{C}$, çalkalama hızı $225 \mathrm{rpm}$ ve serbest $\mathrm{pH}$ değeri 5.2 olarak sabit tutulmuştur. Her bir deney sonunda ortamdan çekilen 5 mL'lik numune (Nuve NF 1215 modele sahip bir cihazda) hızlıca santrifüjlenmiştir. Her bir çözeltideki boyar madde konsantrasyonu, 617 nm de Mapada V-1100 model spektrofotometre ile tayin edilmiş ve herhangi bir andaki adsorpsiyon kapasitesi eşitlik 1' den hesaplanmıştır.

$$
q_{e}=\frac{\left(C_{0}-C_{e}\right) V}{m}
$$

Denklemdeki $\mathrm{C}_{0}$ ve $\mathrm{C}_{\mathrm{e}}$ sırasıyla, başlangıç ve denge anındaki malahit yeşili konsantrasyonlarını (mg. $\left.\mathrm{L}^{-1}\right), \mathrm{V}$ çözelti hacmini (L), m adsorbent miktarını ( $\mathrm{g}$ ) ve $\mathrm{q}_{\mathrm{e}}$ ise denge anındaki adsorpsiyon miktarını (mg. $\left.\mathrm{g}^{-1}\right)$ ifade etmektedir.

\section{Kinetik İnceleme}

En iyi adsorpsiyon şartlarını belirleyebilmek için adsorpsiyon kinetiğinin incelenmesi gerekir. Adsorpsiyon hızl, adsorpsiyon proseslerinin modellenmesinde oldukça önemli olup çözelti arayüzeyinde adsorbe edilen maddenin kalma süresi ile nas1l kontrol edilebileceğini göstermektedir. Deneysel çalışmalarda, sulu çözeltilere ait adsorpsiyon prosesleri için, literatüre göre kullanılan en yaygın kinetik modeller (yalancı birinci mertebe, yalancı ikinci mertebe, partikül içi difüzyon ve Elovich modelleri) denenmiştir [13].

\section{Yalancı Birinci Mertebe Kinetik Model}

Yalanc1 birinci mertebe kinetik modeli aşağıdaki gibi ifade edilmektedir [14]:

$\log \left(q_{e}-q_{t}\right)=\log q_{e}-\frac{k_{1} t}{2.303}$

Burada, $\mathrm{q}_{\mathrm{t}}$ (mg. $\mathrm{g}^{-1}$ ) herhangi bir $\mathrm{t}$ anında adsorplanmış madde miktarı ve $\mathrm{k}_{1}\left(\mathrm{dk}^{-1}\right)$ adsorpsiyon hiz sabitidir. $\mathrm{k}_{1}$ ve $\mathrm{q}_{\mathrm{e}}$ nicelikleri, $\mathrm{t}$ ' ye karşı $\log \quad\left(\mathrm{q}_{\mathrm{e}}-\mathrm{q}_{\mathrm{t}}\right) \quad$ grafiğinden hesaplanmaktadır.

\section{Yalancı İkinci Mertebe Kinetik Model}

$\mathrm{Bu}$ kinetik model, denklem (3) ile formülize edilmektedir [15]:

$\frac{t}{q_{t}}=\frac{1}{k_{2} q_{e}^{2}}+\frac{1}{q_{e}} t$

$\mathrm{Bu}$ modelde, $\mathrm{k}_{2}\left(\mathrm{~g} \cdot \mathrm{mg}^{-1} \cdot \mathrm{dk}^{-1}\right)$ adsorpsiyon $\mathrm{h} 1 \mathrm{z}$ sabitini ve $\mathrm{q}_{\mathrm{t}}\left(\mathrm{mg}_{\mathrm{g}} \mathrm{g}^{-1}\right)$ ise herhangi bir $\mathrm{t}$ anında adsorplanan madde miktarını ifade etmektedir. $\mathrm{t}$ değerlerine karşıllk $\mathrm{t} / \mathrm{q}_{\mathrm{t}}$ grafiğinden, $\mathrm{q}_{\mathrm{e}} \mathrm{ve} \mathrm{k}_{2}$ parametreleri hesaplanmaktadır.

\section{Partikül İçi Difüzyon Modeli}

Partikül içi difüzyon modeli aşağıdaki şekilde ifade edilmektedir [16].

$q_{t}=K_{i} \sqrt{t}+C$

Denklemde; $\mathrm{K}_{i} \quad\left(\mathrm{mg}_{\mathrm{g}} \mathrm{g}^{-1} \cdot \mathrm{dk}^{-1 / 2}\right)$, partikül içi difüzyon hız sabiti ve $\mathrm{C}(\mathrm{mg} / \mathrm{g})$, adsorbent ile adsorbat arasındaki tabaka kalınlığına ait bir 
sabittir. $\mathrm{K}_{i}$ ve $\mathrm{C}$ değerleri, $\mathrm{q}_{\mathrm{t}-} \sqrt{t}$ eğrisinden hesaplanmaktadır.

\section{Elovich Kinetik Modeli}

$\mathrm{Bu}$ kinetik modeli ifade eden denklem aşağıda verilmiştir [17]:

$q_{t}=\frac{\ln (\alpha \beta)}{\beta}+\frac{\ln t}{\beta}$

Bu eşitlikte; $\alpha\left(\mathrm{mg} \cdot \mathrm{g}^{-1} \cdot \mathrm{dk}^{-1}\right)$, başlangıç sorpsiyon hızını ve $\beta$ (g.mg- ${ }^{-1}$ ) ise, sorpsiyon için gerekli yüzey aktivasyon enerjisini temsil etmektedir.

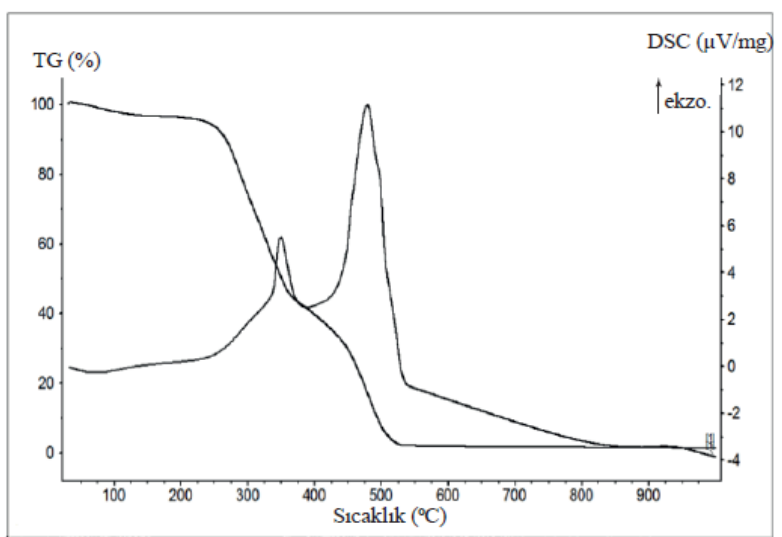

a) Adsorpsiyon öncesi $q_{t}^{\prime}$ ye karş1 $\ln (\mathrm{t})$ eğrisinden, $\alpha$ ve $\beta$ sabitleri hesaplanmıştır.

\section{Bulgular ve Tartışma}

\section{TG/DSC Analizleri}

Şeftali çekirdeğinin adsorpsiyon öncesi ve sonrası TG/DSC grafikleri Şekil 1' de ve DTG grafiği ise Şekil 2'de verilmiştir.

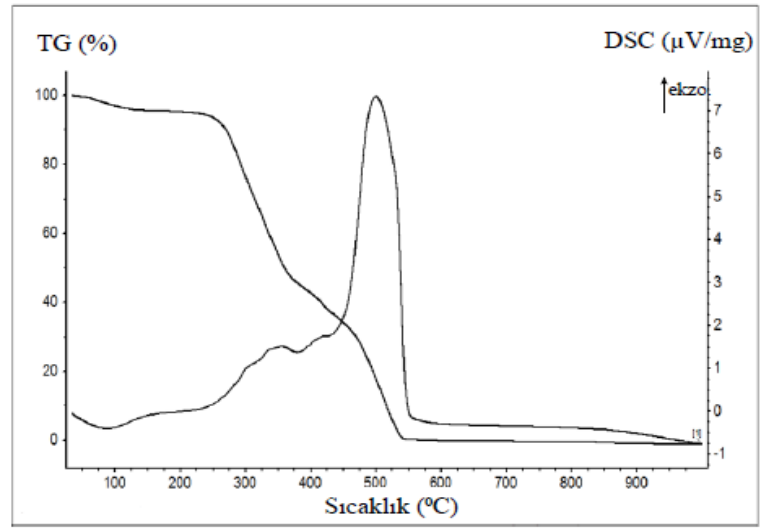

b) Adsorpsiyon sonrast

Şekil 1. Şeftali çekirdeğinin TG-DSC grafikleri

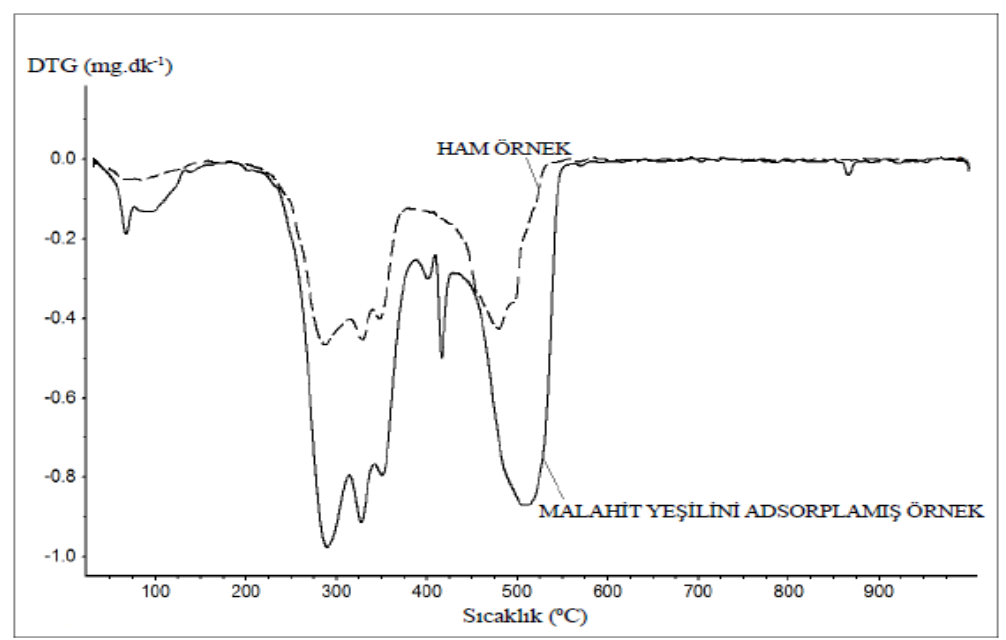

Şekil 2. Şeftali çekirdeğinin DTG grafĭgi

TG/DSC analizinden, şeftali çekirdeğinin bozunması, yaklaşı $25-150^{\circ} \mathrm{C}, 200-380^{\circ} \mathrm{C}$ ve $380-580^{\circ} \mathrm{C}$ sıcaklıkları olmak üzere üç basamakta gerçekleşmektedir. Nemin uzaklaştı̆̆ $25-150^{\circ} \mathrm{C}$ aralığında, adsorpsiyon öncesi ve sonrasında, şeftali çekirdeğinin 
ağırlık kaybı \%6 civarında olmaktadır. Yine bu grafikten, adsorpsiyon öncesi ve sonrasinda (200-380 ${ }^{\circ} \mathrm{C}$ aralığında) yaklaşık \%48'lik bir kütle kaybı olduğu görülmüş, DSC eğrisinde, özellikle adsorpsiyon öncesinde, belirgin bir ekzotermik pikin olduğu gözlenmiştir. 380$580^{\circ} \mathrm{C}$ aralığında ise lignin, daha geniş bir sıcaklık aralığında bozunmaktadır. TG/DSC verilerine göre, lignindeki bozunmanın genellikle bu bölgeye karşıllk geldiği görülmektedir. Maksimum bozunma sıcaklığı yaklaşık olarak $490^{\circ} \mathrm{C}$ olup, bu ayrışmaya karşılık gelen kütle kaybı ise \%44 civarındadır. Yani, DSC eğrisinde bu bölgeye ait ekzotermik bir pik oluşmaktadır.
DTG grafiğinde, adsorpsiyon sonrası (yaklaşık 230-390 ${ }^{\circ} \mathrm{C}$ bölgesi), hemiselüloz, selüloz ve ligninin ayrışma sıcaklığını desteklemektedir. Ayrıca aynı eğrideki $410-430^{\circ} \mathrm{C}$ aralığı da, adsorplanmış malahit yeşilinin parçalanma sıcaklığını temsil edebilir.

\section{XRD Analizleri}

Ham şeftali çekirdeğinin XRD grafiği Şekil 3'de gösterilmiştir. Grafik incelendiğinde, 2Ө' nın özellikle $22^{0}$ ve kısmen $33^{0}$ değerlerine ait karakteristik piklere karşılık geldiği ve lignin, selüloz ve hemiselüloz gibi yapıların varlığından dolayı şeftali çekirdeğinin amorf bir yapıya sahip olduğu söylenebilir.

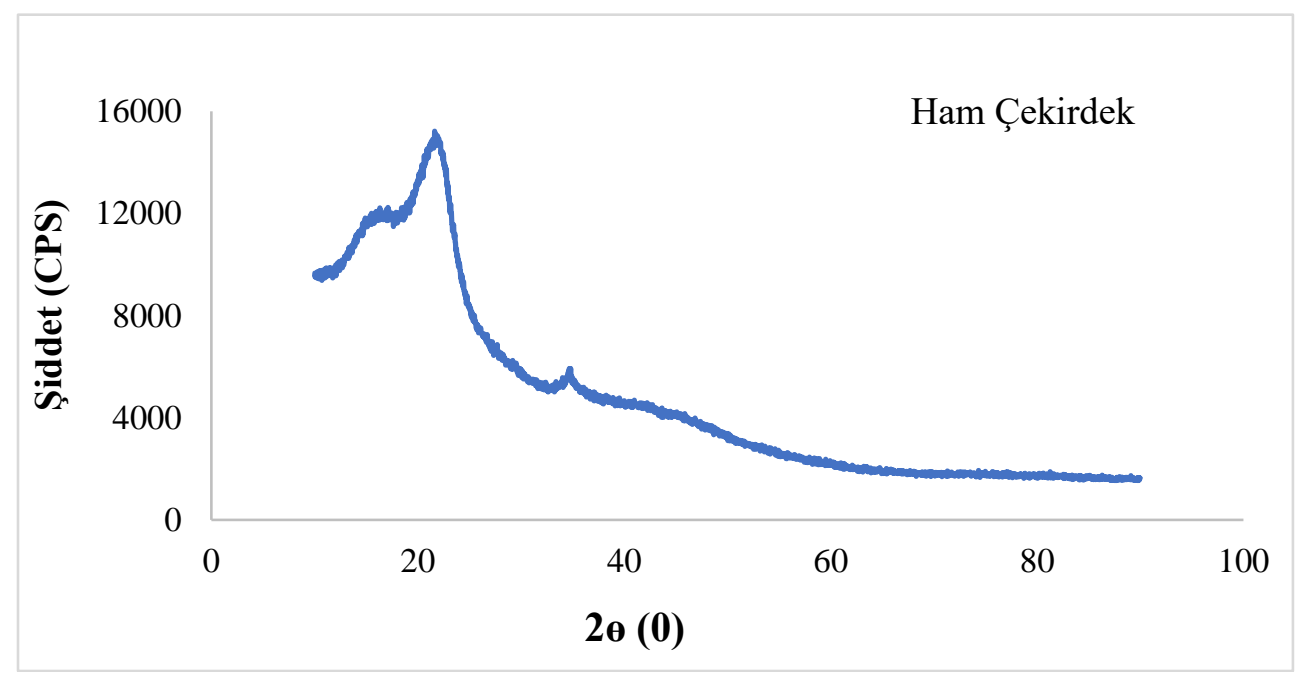

Şekil 3. Ham şeftali çekirdeğinin XRD grafiği

\section{SEM Analizleri}

Şeftali çekirdeği kabuğunun adsorpsiyon öncesi ve sonrasına ait SEM görüntüleri Şekil 4 ve 5 'de verilmiştir. Adsorpsiyon öncesinde, heterojen bir karakterde olan yüzeyin kısmen küresel gözeneklere, kısmen de silindirik ve kompakt oluşumlara sahip olduğu belirtilebilir. Adsorpsiyon sonrasında ise, gözeneklerin tamamen absorbat ile işgal edildiği ve dolayısıyla heterojenliğin kısmen kaybolarak homojen bir yüzey özelliğine doğru değişim gösterdiği ifade edilebilir. 


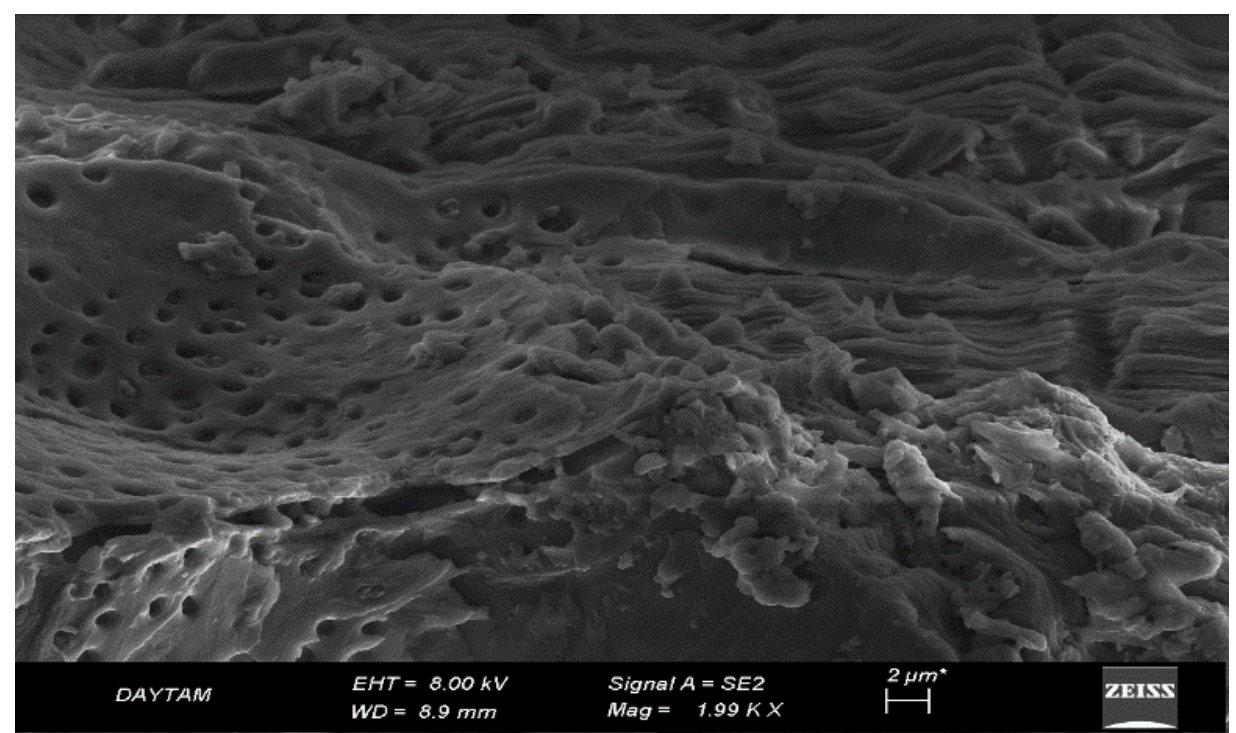

Şekil 4. Adsorpsiyon öncesi SEM görüntüsü

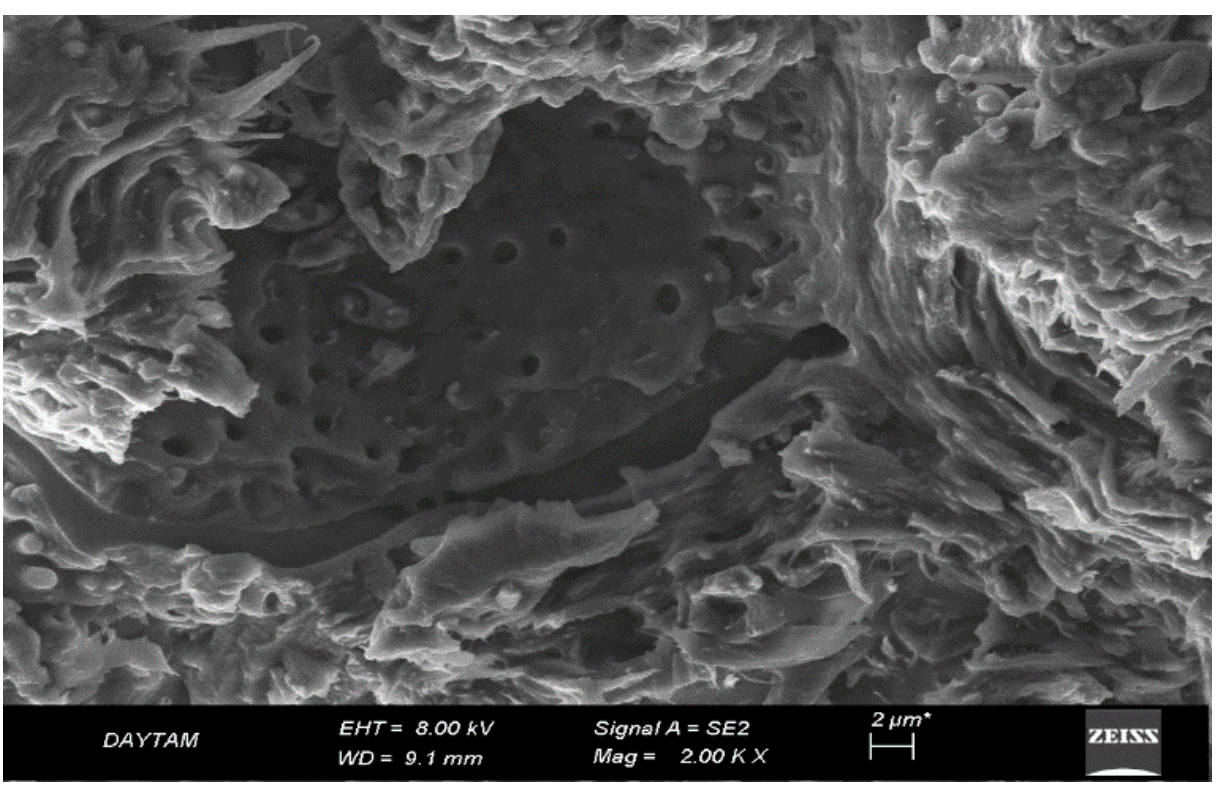

Şekil 5. Adsorpsiyon sonrası SEM görüntüsü

\section{Adsorpsiyon Kinetiği}

Adsorpsiyon prosesine ait kinetik çalışmalarında, yalancı birinci mertebe, yalancı ikinci mertebe, partikül içi difüzyon ve Elovich modelleri uygulanmıştır. Şekil 6-9, bu modellere ait grafikleri temsil etmektedir. Modellere ait parametre değerleri ve korelasyon katsayıları ise Tablo 4'te verilmiştir. Bu tabloya göre, korelasyon katsayılarına ait en uygun modelin yalancı ikinci mertebe model olduğu gözlenmiştir. Sulu çözeltilerden malahit yeşilinin giderilmesi üzerine yapılan çalışmalarda da benzer sonuçlar gözlenmiştir [18-20]. Ayrica, bu modele ait adsorpsiyon kapasitesinin, deneysel ve hesaplanmış değerlerinin de birbirine yakın olduğu görülmüştür. Bu sonuçlar Tablo 5 'te verilmiştir. 


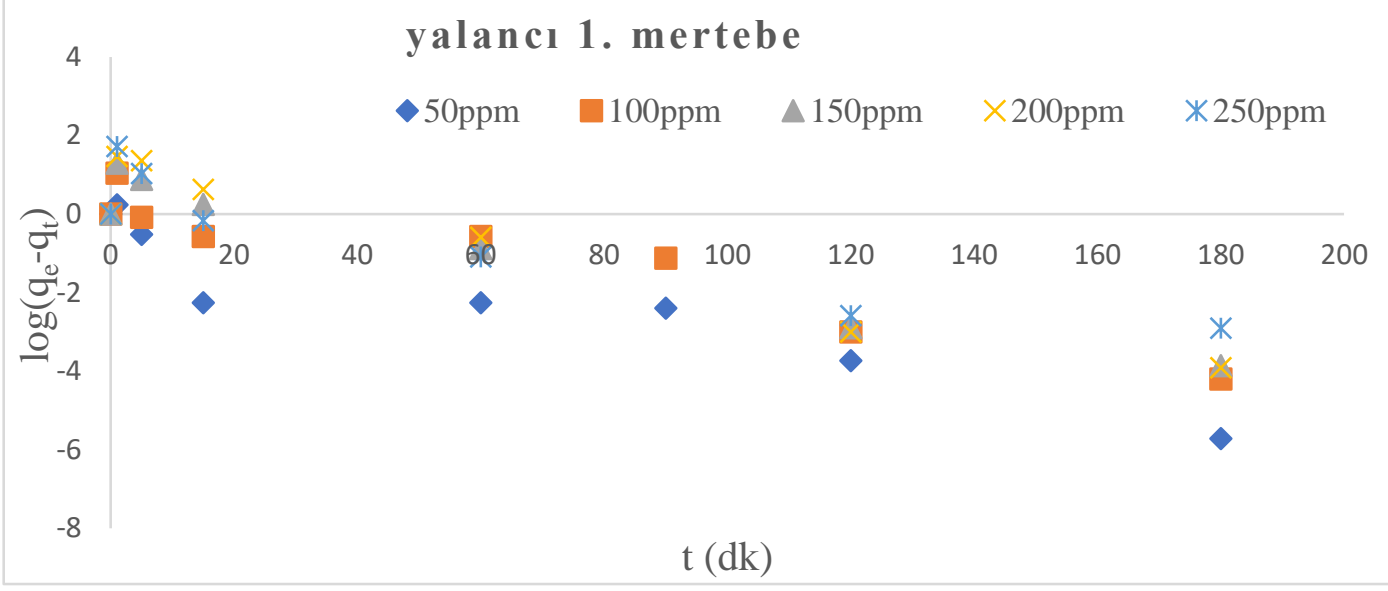

Şekil 6. Yalancl-birinci mertebe kinetik modeli

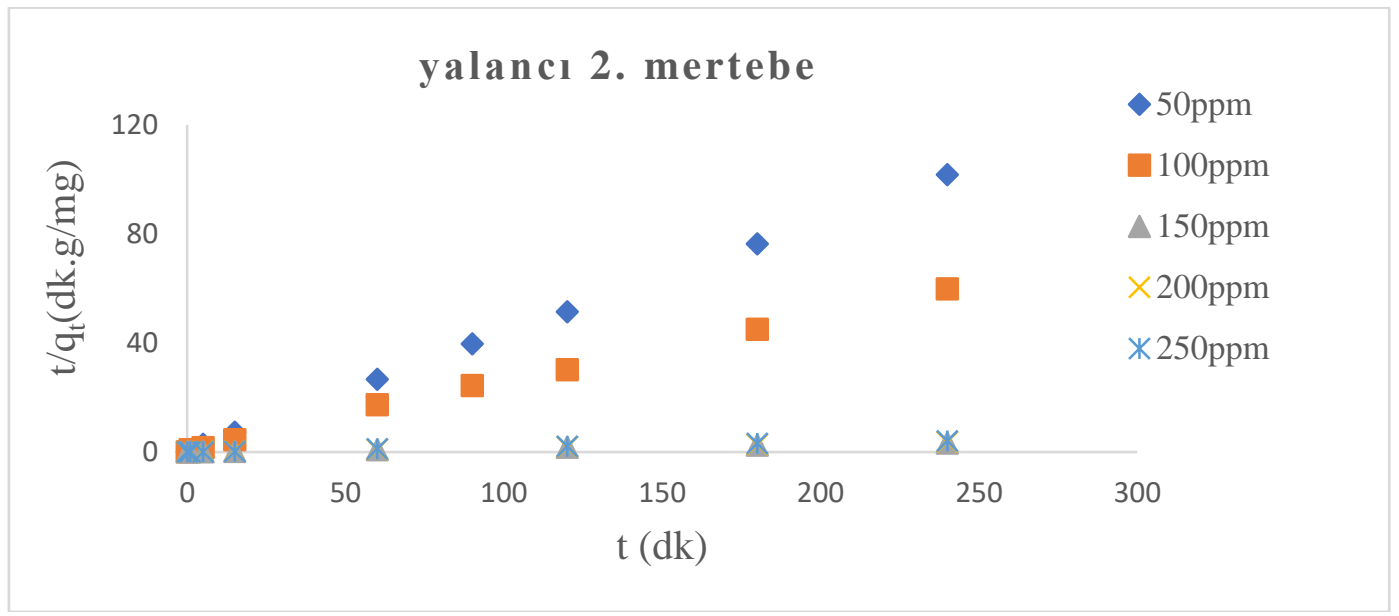

Şekil 7. Yalancl-ikinci mertebe kinetik modeli

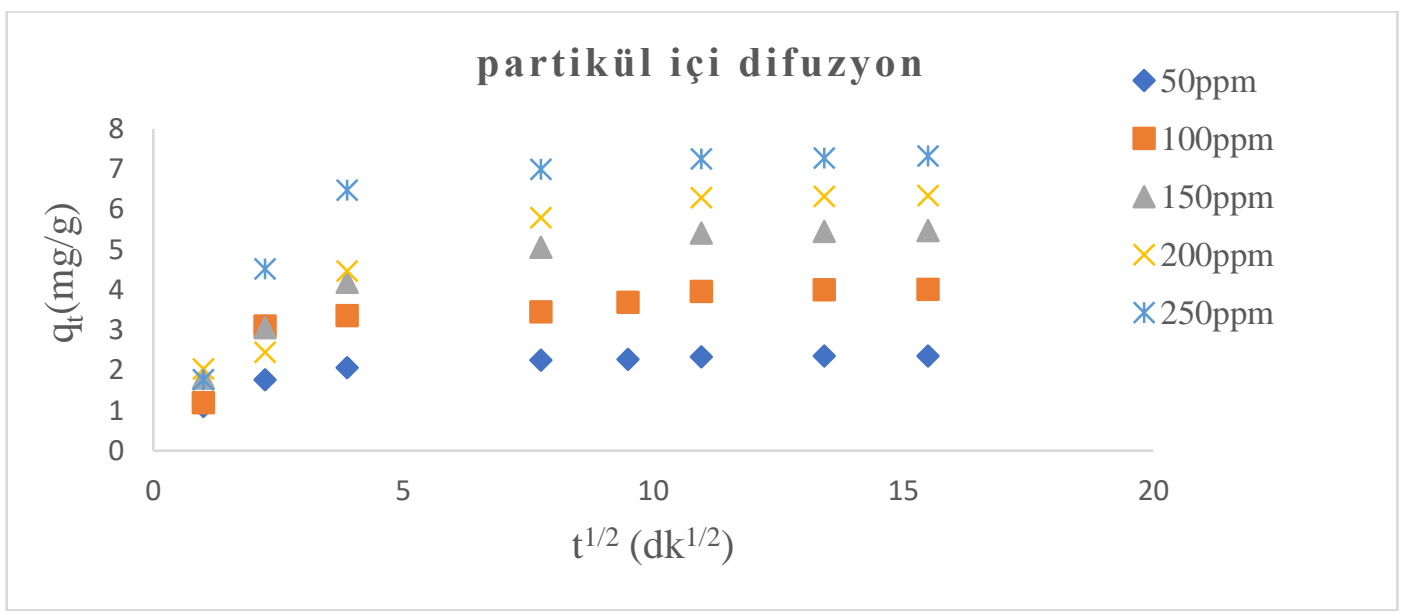

Şekil 8. Partikül içi difüzyon modeli 


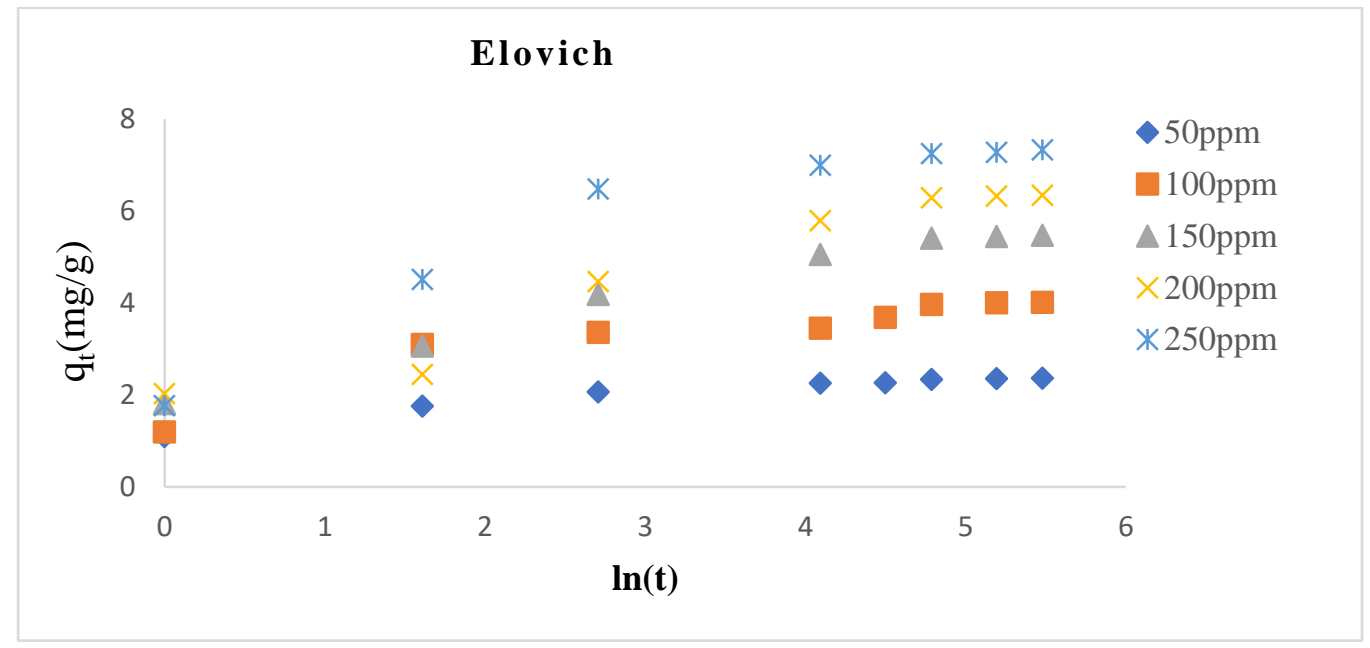

Şekil 9. Elovich kinetik modeli

Tablo 4. Kinetik modellere ait parametre değerleri ve korelasyon katsayıları

\begin{tabular}{lcccccc}
\hline \multirow{2}{*}{$\begin{array}{l}\text { Kinetik } \\
\text { model }\end{array}$} & Parametre & \multicolumn{5}{c}{ Konsantrasyon (ppm) } \\
\cline { 3 - 7 } & & 50 & 100 & 150 & 200 & 250 \\
\hline \multirow{2}{*}{$\begin{array}{l}\text { Yalancı I. } \\
\text { mertebe }\end{array}$} & $\mathrm{k}_{1}$ & 0.071 & 0.056 & 0.061 & 0,066 & 0.052 \\
& $\mathrm{q}_{\mathrm{e}}$ & 0.180 & 2.360 & 5.190 & 9.700 & 4.600 \\
& $\mathrm{R}^{2}$ & 0.860 & 0.900 & 0.940 & 0.920 & 0.850 \\
\hline \multirow{2}{*}{$\begin{array}{l}\text { Yalancı II. } \\
\text { mertebe }\end{array}$} & $\mathrm{k}_{2}$ & 0.240 & 0.070 & 0.060 & 0.040 & 0.060 \\
& $\mathrm{q}_{\mathrm{e}}$ & 2.370 & 4.045 & 5.534 & 6.439 & 7.384 \\
Partikül içi & $\mathrm{R}^{2}$ & 0.999 & 0.998 & 0.999 & 0.999 & 0.999 \\
difüzyon & $\mathrm{k}_{\mathrm{i}}$ & 0.068 & 0.130 & 0.220 & 0.300 & 0.290 \\
& $\mathrm{C}$ & 1.515 & 2.2287 & 2.603 & 2.455 & 3.662 \\
\hline \multirow{2}{*}{$\begin{array}{l}\text { Elovich } \\
\text { Modeli }\end{array}$} & $\mathrm{R}^{2}$ & 0.675 & 0.626 & 0.789 & 0.828 & 0.627 \\
& $\alpha$ & 79.350 & 24.400 & 12.530 & 6.540 & 15.340 \\
\hline
\end{tabular}

Tablo 5. Yalancı II. mertebe modele ait hesaplanan ve deneysel $q_{e}$ değgerleri

\begin{tabular}{ccccc}
\hline Deneysel sabitler & & & & \\
Konsantrasyon & $\mathrm{k}_{2}$ & $\mathrm{q}_{\mathrm{e}}$ (hesaplanan) & $\mathrm{R}^{2}$ & $\mathrm{q}_{\mathrm{e}}$ (deneysel) \\
\hline $50 \mathrm{ppm}$ & 0.240 & 2.370 & 0.999 & 2.359 \\
$100 \mathrm{ppm}$ & 0.070 & 4.045 & 0.998 & 4.015 \\
$150 \mathrm{ppm}$ & 0.060 & 5.534 & 0.999 & 5.469 \\
$200 \mathrm{ppm}$ & 0.040 & 6.439 & 0.999 & 6.342 \\
$250 \mathrm{ppm}$ & 0.060 & 7.384 & 0.999 & 7.328 \\
\hline
\end{tabular}




\section{Sonuçlar}

Yapısında lignin, selüloz ve hemiselüloz içeren şeftali çekirdeği kabuğunun karakterizasyonu ve sulu ortamda malahit yeşilinin giderimine ait bir kinetik çalışması yapılmıştır. Karakterizasyon çalışmaları için SEM, XRD, TG/DSC, DTG ve yüzey analizleri yapılmıştır.

SEM görüntülerinden, küresel gözenekli adsorbentin, silindirik ve kompakt oluşumlarla beraber heterojen bir yapıda olduğu ve XRD analizi sonucuna göre ise, yapının amorf bir karakterde olduğu görülmüştür.

TG/DSC analizlerinden, şeftali çekirdeğinin $25-150^{\circ} \mathrm{C}, 200-380^{\circ} \mathrm{C}$ ve $380-580^{\circ} \mathrm{C}$ sicaklık aralıklarında bozunduğu gözlenmiştir. DTG grafiğinde, adsorpsiyon sonrası yaklaşık 230$390^{\circ} \mathrm{C}$ bölgesi, hemiselülöz, selülöz ve ligninin ayrışma sıcaklığını desteklemiştir.

Şeftali çekirdeği kabuğuna ait yüzey analizlerinden, katının, $17.36 \mathrm{~m}^{2} \cdot \mathrm{g}^{-1}{ }^{1} \mathrm{l} 1 \mathrm{k}$ bir yüzey alanına, $0.016 \mathrm{~cm}^{3} \cdot \mathrm{g}^{-1}$ l $1 \mathrm{k}$ bir por hacmine ve $3.37 \mathrm{~nm}$ 'lik ortalama bir por çapına sahip olduğu belirlenmiştir.
Adsorpsiyon prosesine ait kinetik incelemeler sonucunda, prosesin en yüksek korelasyon katsayısına $\quad\left(\mathrm{R}^{2}>0.99\right)$ sahip olan ikinci mertebeden kinetik modele uyduğu tespit edilmiştir. Yapılan çalışma sonunda, kullanılan çekirdek kabuğunun, malahit yeşili veya benzer tehlikeli atıkların uzaklaştırılması için belli bir potansiyele sahip uygun bir adsorbent olabileceği öngörülmüştür.

\section{Teșekkür -}

Fon/Finansman bilgileri Yazarlar bu çalışmanın araştırması, yazarlığı veya yayınlanması için herhangi bir mali destek almamışlardır.

\section{Etik Kurul Onayı ve İzinler -}

Çıkar çatışmaları/Çatışan çıkarlar Yazarlar çıkar çatışması olmadığını beyan eder.

Yazarların Katkısı Tüm yazarlar, bu çalışmanın planlanmasına, yürütülmesine veya analizine yazar olarak dahil edilmek üzere yeterince katkıda bulunmuştur. Tüm yazarlar makalenin son halini okumuş ve onaylamıştır.

\section{Kaynaklar}

[1] Kupeta, A. J. K., Naidoo, E. B., \& Ofomaja, A. E. (2018). Kinetics and equilibrium study of 2nitrophenol adsorption onto polyurethane cross-linked pine cone biomass. Journal of Cleaner Production, 179, 191-209. https://doi.org/10.1016/j.jclepro.2018.01.034

[2] Sartape, A. S., Mandhare, A. M., Jadhav, V. V., Raut, P. D., Anuse, M. A., \& Kolekar, S. S. (2017). Removal of malachite green dye from aqueous solution with adsorption technique using Limonia acidissima (wood apple) shell as low cost adsorbent. Arabian Journal of Chemistry, 10, S3229-S3238. http://dx.doi.org/10.1016/j.arabjc.2013.12.019

[3] Mohamed, A., Ghobara, M. M., Abdelmaksoud, M. K., \& Mohamed, G. G. (2019). A novel and highly efficient photocatalytic degradation of malachite green dye via surface modified polyacrylonitrile nanofibers/biogenic silica composite nanofibers. Separation and Purification Technology, 210, 935-42. https://doi.org/10.1016/j.seppur.2018.09.014 
ISSN: $2536-4383$

[4] Lacin, O., Haghighatnia, A., Demir, F., Sevim, F., \& Laçin, O. (2019). Adsorption characteristics and behaviors of natural red clay for removal of BY28 from aqueous solutions. International Journal of Trend in Scientific Research and Development, 3(2), 1037-1047. https://doi.org/10.31142/ijtsrd21544

[5] Mashkoor, F., \& Nasar, A. (2019). Preparation, characterization and adsorption studies of the chemically modified Luffa aegyptica peel as a potential adsorbent for the removal of malachite green from aqueous solution. Journal of Molecular Liquids, 274, 315-327. https://doi.org/10.1016/j.molliq.2018.10.119

[6] Othman, N. H, Alias, N. H., Shahruddin, M. Z., Bakar, N. F. A., Him, N. R. N., \& Lau, W. J. (2018). Adsorption kinetics of methylene blue dyes onto magnetic graphene oxide. Journal of Environmental Chemical Engineering, 6(2), 2803-2811. https://doi.org/10.1016/j.jece.2018.04.024

[7] Ahmad, M. A., \& Alrozi, R. (2011). Removal of malachite green dye from aqueous solution using rambutan peel-based activated carbon: Equilibrium, kinetic and thermodynamic studies. Chemical Engineering Journal, 71, 510-516. https://doi.org/10.1016/j.cej.2011.04.018

[8] Subbaiah, M. V., \& Kim, D. S. (2016). Adsorption of methyl orange from aqueous solution by aminated pumpkin seed powder: Kinetics, isotherms, and thermodynamic studies. Ecotoxicology and Environmental Safety, 128, 109-17. https://doi.org/10.1016/j.ecoenv.2016.02.016

[9] Türkiye İstatistik Kurumu, Faaliyet raporu, 2011. https://www. tuik.gov.tr/jsp/duyuru/ upload/ FR2011.pdf

[10] Çiçekçi, A., Dönmez, B., Kavci, E., \& Laçin, Ö. (2020). Malahit yeşilinin şeftali çekirdeği kabuğu üzerine adsorpsiyon izotermi ve termodinamiği. Sinop Üniversitesi Fen Bilimleri Dergisi, 5(2), 103 111. https://doi.org/10.33484/sinopfbd.70105

[11] Tang, S. H., \& Zaini, M. A. A. (2017). Malachite green adsorption by potassium salts activated carbons derived from textile sludge: equilibrium, kinetics and thermodynamics studies. Asia-Pacific Journal of Chemical Engineering, 12(1), 159-172. https://doi:10.1002/apj.2063

[12] Papinutti, L., Mouso, N., \& Forchiassin, F. (2006). Removal and degradation of the fungicide dye malachite green from aqueous solution using the system wheat bran-fomes sclerodermeus. Enzyme and Microbial Technology, 39, 848-853. https://doi:10.1016/j.enzmictec.2006.01.013

[13] Crini, G., \& Badot, P. M. (2008). Application of chitosan, a natural aminopolysaccharide, for dye removal from aqueous solutions by adsorption processes using batch studies, a review of recent literature. Progress in Polymer Science, 33, 399-447. https://doi:10.1016/j.progpolymsci.2007.11.001

[14] Lagergren, S. K. (1898). About the theory of so-called adsorption of soluble substances. Sven Vetenskapsakad Handingarl, 24, 1-39.

[15] Ho, Y. S., \& McKay, G. (1999). Pseudo-second order model for sorption processes. Process Biochemistry, 34, 451-465.

[16] Weber, W. J., \& Morris, J. C. (1963). Kinetics of adsorption on carbon from solution. Journal of the Sanitary Engineering Division, 89, 31-60.

[17] Maneerung, T., Liew, J., Dai, Y., Kawi, S., Chong, C., \& Wang, C. H. (2016). Activated carbon derived from carbon residue from biomass gasification and its application for dye adsorption: Kinetics, isotherms and thermodynamic studies. Bioresource Technology, 200, 350-359. http://dx.doi.org/10.1016/j.biortech.2015.10.047 
[18] Al-Qodah, Z. (2000). Adsorption of dyes using shale oil ash. Water Research, 34(17), 4295-4303.

[19] Lunhong, A., Haiyan, H., Zhonglan, C., Xing, W., \& Jiang, J. (2010). Activated carbon/CoFe $\mathrm{O}_{4}$ composites: facile synthesis, magnetic performance and their potential application for the removal of malachite green from water. Chemical Engineering Journal, 156, 243-249. https://doi:10.1016/j.cej.2009.08.028

[20] Azmier, A. M., \& Rasyidah, A. (2011). Removal of malachite green dye from aqueous solution using rambutan peel-based activated carbon: equilibrium, kinetic and thermodynamic studies. Chemical Engineering Journal, 171, 510-516. https://doi.org/10.1016/j.cej.2011.04.018 